\title{
Comparative study of the intestinal parasitism profiles between communities across the 5 municipalities of the Barranquilla metropolitan area, Colombia
}

\section{Luz A. Sarmiento-Rubiano ${ }^{1}\left({ }^{(1)}\right.$, Margarita Filott $^{2}{ }^{(1)}$, Lucila Gómez $^{2}$ (i),

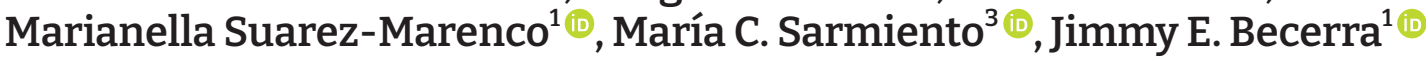

${ }^{1}$ Feeding and Human Behavior Research Group, Metropolitan University, Barranquilla, Colombia

${ }^{2}$ Caribbean Infectious Diseases and Microbial Resistance Research Group, Metropolitan University, Barranquilla, Colombia

${ }^{3}$ Preventive and Community Medicine of Sinú University, Cartagena, Colombia

Received: July 9, 2021

Revised: August 24, 2021

Accepted: September 23, 2021

Corresponding author: Luz A. Sarmiento-Rubiano Feeding and Human Behavior Research Group, Metropolitan University, Street 76 No 42-78, Barranquilla 080020, Colombia E-mail: lusarru@hotmail.com

\section{ABSTRACT}

Objectives: The aim of this study was to compare the rate of parasitism and intestinal parasitism profiles of children who live in relatively proximal communities across the 5 municipalities of the Barranquilla metropolitan area, Colombia.

Methods: In total, 986 fecal samples from children aged 1 to 10 were analyzed using a direct method (physiological saline and lugol) and the zinc sulfate flotation technique. A comparative analysis of the parasitism profiles between sampling locations (7 schools and 3 health centers providing growth and development services) was conducted using principal component analysis (PCA). The presence of Taenia solium antibodies was evaluated by the enzyme-linked immunosorbent assay method in 269 serum samples from the same group of children.

Results: The overall prevalence of intestinal parasitism was 57.6\% (range, 42.1\%-77.6\%) across the sampling areas. The prevalence of helminthiasis was between $4.1 \%$ and $23.7 \%$, and that of intestinal protozoa was between $38.2 \%$ and $73.5 \%$. PCA showed that the parasite profiles of each sampling location shared no common characteristics. A total of $3.0 \%$ of the serum samples were positive for $T$. solium antibodies.

Conclusion: The intestinal parasitism profiles between relatively proximal sampling locations with similar geographic conditions were vastly different, indicating the need to study each small ecological niche on a localized scale to develop more cost-effective interventions for controlling intestinal parasitism.

Keywords: Helminthiasis; Neglected diseases; Parasites; Taenia solium

\section{Introduction}

Intestinal parasites are widely distributed in the world and mainly affect developing countries 
in tropical and subtropical regions where environmental, social, and cultural conditions, including inadequate basic sanitation, a lack of sewage, and inadequate waste management, increase the likelihood of their transmission. School-age children are one of the most vulnerable populations to gastrointestinal parasite infections. Parasitism in children is associated with growth retardation, severe anemia, and impaired learning ability [1]. Approximately 1.5 billion people in the world (24.0\% of the global population) are affected by soil-transmitted helminths, 270 million of whom are preschool-age children. In Latin America, 46 million school-age children live in areas with a high risk of transmission of these parasites [2]. In Colombia, the results of 3 national parasitism surveys carried out in 1965, 1980, and 2014 all found a prevalence rate of more than $80 \%$ for intestinal parasitism among the population despite their vastly different methodological processes [3]. The Colombian Massive Anthelmintic Deworming Guidelines were created in 2013, based on the helminth control guide published by the World Health Organization (WHO). Guidelines include deworming using annual or biannual single doses of albendazole $(400 \mathrm{mg}$ ) or mebendazole $(500 \mathrm{mg}$ ) for eligible groups in the population according to their risk of soil-helminth transmission, with school-age children (5 to 14 years old) being a prioritized group $[4,5]$. In the areas examined in this study, this program was only implemented until the end of 2015.

Several studies have found significant differences in the parasitic profiles of population groups in the same geographic area across different points in time, which gives insight into the dynamics of the evolution of parasitic infections depending on various factors related to the parasite, the host, and the environment [6-8].

The WHO has affirmed that intestinal parasites should be controlled based on chemotherapeutic strategies suited to the target population, but also through routine monitoring and the control of infection dynamics [9,10]. An understanding of the ecology and epidemiology of parasitic diseases and the environmental changes that affect them enables more cost-effective parasite control measures. In this study, the parasite profiles of children under 10 years of age from 10 different locations across the 5 municipalities of the Barranquilla metropolitan area (BMA) were examined, and the results between locations were compared.

\section{Materials and Methods}

In this descriptive, correlational cross-sectional study, 986 fecal samples were collected from children under 10 years of age ( 482 females and 504 males) at 10 locations ( 7 schools and 3 health centers providing growth and development services). All sites were located in urban areas in the 5 municipalities of the BMA. Samples were collected between June 2014 and September 2015.

Since species such as Taenia solium are difficult to diagnose using conventional coproanalysis techniques and Colombia is considered an endemic area for this parasite, the presence of anti-T. solium immunoglobulin G (IgG) antibodies was evaluated in 269 serum samples from the group of children examined in this study.

\section{Area Description}

The BMA is located in the Department of Atlántico, Colombia, and includes the municipalities of Soledad, Galapa, Malambo, Puerto Colombia, and Barranquilla district. The BMA borders the Caribbean Sea to the north, the Magdalena River to the east, and other municipalities to the southwest. The BMA has an area of $520 \mathrm{~km}^{2}$ and a dry tropical climate, with an average temperature of $28^{\circ} \mathrm{C}$. Figure 1 shows a map of the BMA including its municipalities and the sample locations in this study. The population of the Department of Atlántico

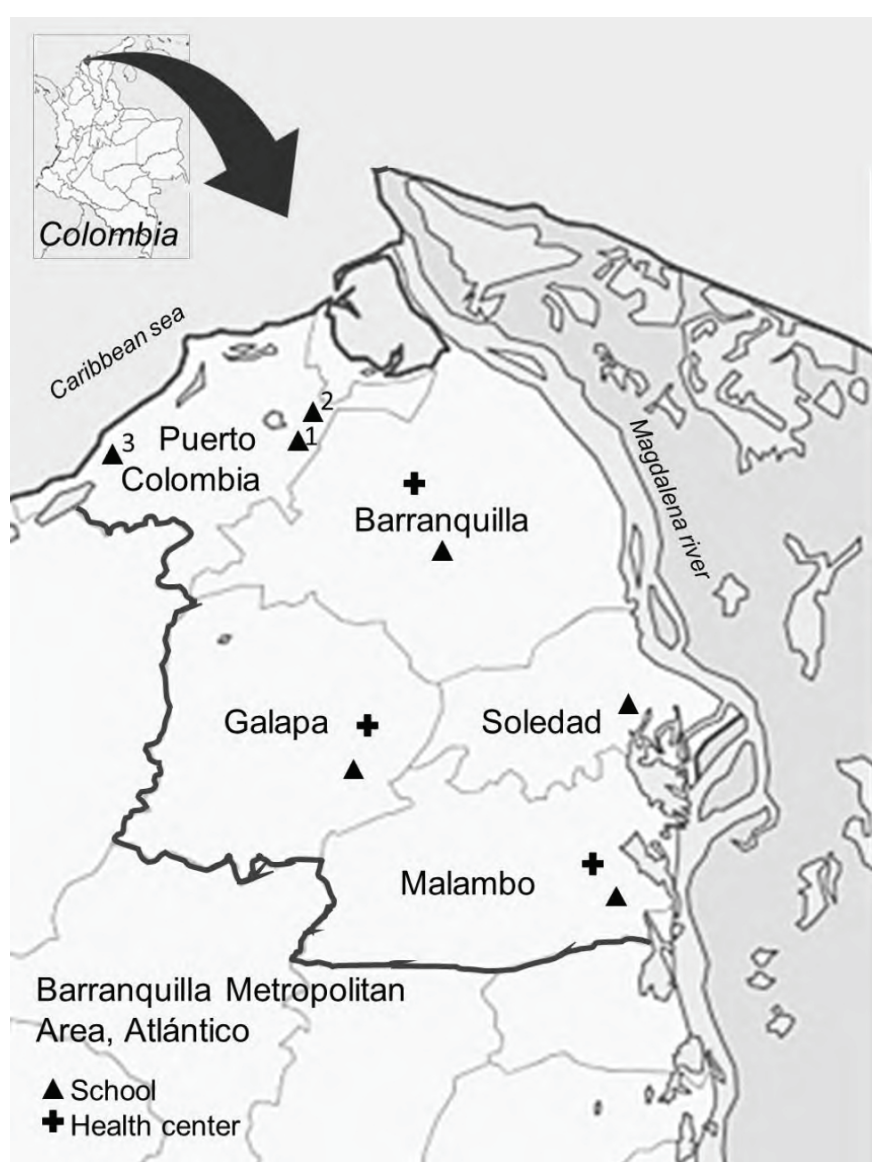

Figure 1. Municipalities of the Barranquilla metropolitan area and sampling locations within the Department of Atlántico, Colombia. 
according to the National Department of Statistics for 2015 was $2,461,001$ inhabitants, of which approximately $82.3 \%$ were located in the BMA and 648,884 were under 14 years of age [11]. With 986 fecal samples, a confidence level of greater than $95 \%$ was achieved. The differences between municipalities related to factors such as poverty, education, health services, access to home public services, basic sanitation, and housing are reflected in the multidimensional poverty index (MPI) of each municipality. In 2015, the MPI was 37.2\% in the District of Barranquilla, 78.3\% in Galapa, $62.5 \%$ in Malambo, $42.3 \%$ in Puerto Colombia, and $45.4 \%$ in Soledad [12].

\section{Collection and Analysis of Samples}

After obtaining prior authorization and the directives from each participating institution, the project was explained to as many children's parents as possible. The appropriate way to collect the stool sample was explained and the containers for sample collection were provided to them. The exclusion criterion was children with severe gastrointestinal symptoms that required urgent medical attention. At a previously determined date and time, the parents who voluntarily agreed to take part in the study delivered the fecal samples of the children which were immediately transported under refrigerated conditions to laboratories for processing. The sample analysis was conducted via a direct examination with a physiological saline solution and a 3\% iodine solution. Additionally, the fecal concentration technique was performed with a zinc sulfate concentration of 33.0\% for the concentration of eggs ( $2 \mathrm{~g}$ of feces were homogenized in $10 \mathrm{~mL}$ of water, filtered through gauze, and centrifuged in a $15 \mathrm{~mL}$ tube for 2 minutes at $400 \times g$, and the sediment was resuspended in a zinc sulfate solution) $[13,14]$.

In addition, 269 serum samples were collected from a portion of the children who were in a good state of health after obtaining consent from their parents. The venous blood samples were taken from the children after fasting. Using a closed vacuum tube without anticoagulant, the samples were transported under refrigeration to the clinical laboratory and immediately centrifuged, and the serum was stored at $-80^{\circ} \mathrm{C}$ until use.

The presence of anti-T. solium IgG antibodies in serum was determined using the commercial anti-T. solium IgG human enzyme-linked immunosorbent assay (ELISA) kit (ab108770; Abcam, Cambridge, UK). This kit is specified for the detection of antibodies against $T$. solium by indirect ELISA, using a crude cysticercus lysate of $T$. solium as an antigen. The test has a sensitivity of $93.8 \%$ and a specificity greater than $95 \%$. The analysis protocol was performed according to the manufacturer's instructions using the Stat
Fax 303 Plus Microstrip Reader (Minneapolis, MN, USA).

\section{Statistical Analysis}

An exploratory descriptive analysis of the results was conducted to determine the absolute and relative frequency of the parasites present in the samples, and principal component analysis (PCA) was conducted to compare the results between sampling locations using the XLSTAT program for Excel (Addinsoft Inc., Paris, France). This test allowed us to evaluate the similarities between the parasite profiles of each location and municipality. The results concerning the frequency of parasitism, helminthiasis, and intestinal parasitic protozoa from each sampling location and municipality were compared using the chi-square test for categorical variables with the same statistical program. Descriptive analysis was used to determine the presence of anti-T. solium IgG antibodies in the serum.

\section{Ethical Considerations}

This study was approved by the Ethics Committee of the Metropolitan University (Ref. 2014-11), and it was based on the Declaration of Helsinki and Resolution 8430 of 1993 of the Ministry of Health and Social Protection in Colombia, which establishes the scientific, technical, and administrative standards for research in health. It was classified as minimal risk. Blood samples were taken after obtaining informed consent from the children's parents or legal representative. Participation in the project was voluntary, and the results of the fecal analyzes were shared with the participants so that they could seek in the Public Health Service, corresponding treatment if necessary. Positive findings regarding the presence of $T$. solium IgG antibodies in serum samples did not suggest the presence of an active infection and only had epidemiological value. Since the children showed apparent good health, the ELISA test results were not provided. The analysis and publication of the results were carried out without any data that could have revealed the identities of individual participants or information that could compromise their privacy.

\section{Results}

We analyzed 986 stool samples from children under 10 years of age at 10 sampling locations across the 5 municipalities of the BMA. In total, 568 of the children had some intestinal parasites (57.6\%), with the District of Barranquilla showing the lowest frequency of parasitism (47.6\%) and Soledad municipality showing the highest (73.5\%). Soil-transmitted helminth infection was present in $12.0 \%$ of the total study population, with the highest percentages being found 
in Puerto Colombia and Malambo, at $16.5 \%$ and $15.9 \%$, respectively, followed by Soledad (8.2\%), Barranquilla district (7.5\%), and Galapa (5.7\%), where lower rates were observed. Only 1 child had 4 different helminth species, and 1 had 3 different types of helminth species. However, 18 children had 2 different helminth species (1.8\%), while 98 (9.9\%) had 1 species only. A total of $53.5 \%$ of the children analyzed had intestinal parasitic protozoa, with a maximum of 4 different species $(n=3)$ being found. A combination of helminths and protozoa was found in $7.9 \%$ of the children. Of the 568 parasitized children, 41.4\% ( $n=235)$ had more than 1 intestinal parasite. Table 1 shows the frequency of parasitism by municipality. Certain similarities were observed in the rates of parasitism between Barranquilla district and Galapa and between Malambo and Puerto Colombia, but such similarities were not observed when comparing the sampling locations in each municipality (Table 2). No statistically significant differences were found in parasitism according to sex.

The most frequent helminth in the BMA was Trichiuris trichiura (7.6\%) followed by Ascaris lumbricoides (4.5\%). The sampling location with the highest rate of helminthiasis was a school in Puerto Colombia (23.7\%), where a single case of hookworm was also found. Across all of the municipalities in the BMA, Strongyloides sp. infection was observed in only
1 child in the Barranquilla district. This study did not test for the presence of eggs or proglottids of Taenia sp. in the evaluated samples.

The highest proportion of infection with intestinal parasite protozoa was observed at a school in Malambo (77.6\%), and the lowest proportion was observed at a health center in Galapa (38.2\%). The most common protozoa were Blastocystis sp. (26.1\%), the proportion of which varied between $5.9 \%$ and $51.0 \%$ across different sampling locations, and Giardia sp. (15.2\%), the proportion of which varied between $8.6 \%$ and $32.1 \%$ (Table 2). The highest frequency of Blastocystis sp. was found in Soledad (51.0\%), and the highest frequency of Giardia sp. was found in Malambo (18.5\%).

PCA was conducted to identify relationships between the variables (the frequency of parasite species and sampling locations) according to their similarities using Pearson's correlation coefficient. Figure 2 is a graphic representation of factors 1 and 2, which had a cumulative variance of $51.3 \%$. The main components of factor 1 (cumulative variance, 31.3\%) were Enterobius sp. (20.9\%), T. trichiura (15.7\%), and Uncinaria (15.0\%). The main components of factor 2 (cumulative variance, 20.0\%) accumulated variance were $A$. lumbricoides (22.9\%), Blastocystis sp. (18.3\%), and Entamoeba coli (14.1\%). A cumulative variance of $69.7 \%$ was reached by the inclusion of factor 3 and

Table 1. The pravelence of parasitism by municipality

\begin{tabular}{|c|c|c|c|c|c|c|}
\hline \multirow[b]{2}{*}{ Parasitism type } & \multicolumn{6}{|c|}{ Municipalities of the BMA } \\
\hline & $\begin{array}{l}\text { District of } \\
\text { Barranquilla } \\
(n=359)\end{array}$ & $\begin{array}{l}\text { Galapa } \\
(n=70)\end{array}$ & $\begin{array}{l}\text { Malambo } \\
(n=157)\end{array}$ & $\begin{array}{l}\text { Puerto } \\
\text { Colombia } \\
(n=351)\end{array}$ & $\begin{array}{l}\text { Soledad } \\
(n=49)\end{array}$ & $\begin{array}{l}\text { Total BMA } \\
(n=986)\end{array}$ \\
\hline Parasitism & $47.6^{a)}$ & $50.0^{\mathrm{a})}$ & $64.3^{\mathrm{b})}$ & $64.1^{\mathrm{b})}$ & $73.5^{c)}$ & 57.6 \\
\hline Helminths & $7.5^{\mathrm{a})}$ & $5.7^{\mathrm{b})}$ & $15.9^{\mathrm{a})}$ & $16.5^{\mathrm{a})}$ & $8.2^{\mathrm{a})}$ & 12.0 \\
\hline Protozoa & $44.6^{\mathrm{a})}$ & $47.1^{\mathrm{a})}$ & $60.5^{\mathrm{b})}$ & $58.1^{\text {b) }}$ & $73.5^{c)}$ & 53.5 \\
\hline Poly-infection & $34.5^{\mathrm{a})}$ & $40.0^{a)}$ & $49.5^{\mathrm{a})}$ & $41.8^{\mathrm{a})}$ & $50.0^{\mathrm{a})}$ & 41.4 \\
\hline \multicolumn{7}{|l|}{ Parasite species } \\
\hline Entamoeba hystolitica & 5.6 & 7.1 & 6.4 & 6.6 & 6.1 & 6.2 \\
\hline Entamoeba coli & 7.5 & 21.4 & 19.1 & 15.7 & 16.3 & 13.7 \\
\hline lodamoeba sp. & 0.3 & 1.4 & 0.6 & 0.3 & 2.0 & 0.5 \\
\hline Blastocystis sp. & 26.7 & 27.1 & 29.3 & 20.2 & 51.0 & 26.1 \\
\hline Giardia sp. & 13.7 & 11.4 & 18.5 & 15.7 & 18.4 & 15.2 \\
\hline Endolimax nana & 7.8 & 8.6 & 14.7 & 19.1 & 24.5 & 13.8 \\
\hline Ascaris lumbricoides & 2.5 & 1.4 & 3.2 & 8.3 & 0 & 4.5 \\
\hline Trichiuris trichiura & 3.6 & 1.4 & 12.1 & 10.8 & 8.2 & 7.6 \\
\hline Enterobius sp. & 0.8 & 0 & 0.6 & 1.1 & 0 & 0.8 \\
\hline Hymenolepis nana & 1.1 & 2.9 & 1.9 & 0.9 & 0 & 1.2 \\
\hline Uncinaria sp. & 0 & 0 & 0 & 0.3 & 0 & 0.1 \\
\hline Strongyloides sp. & 0.3 & 0 & 0 & 0 & 0 & 0.1 \\
\hline
\end{tabular}

BMA, Baranquilla metropolitan area.

${ }^{a-c)}$ Frequencies (\%) in the same row that do not share the superscript letter are statistically significantly different (chi-square test, $\left.p<0.05\right)$. The frequency of poly-infections was calculated in relation to the number of children with a positive result for more than 1 species of intestinal parasites. 
Table 2. The rate of parasitism for each sampling location in each municipality of the BMA

\begin{tabular}{|c|c|c|c|c|c|c|c|c|c|c|}
\hline \multirow[b]{2}{*}{ Parasitism type } & \multicolumn{2}{|c|}{ Barranquilla district } & \multicolumn{2}{|c|}{ Galapa } & \multicolumn{2}{|c|}{ Malambo } & \multicolumn{3}{|c|}{ Puerto Colombia } & \multirow{2}{*}{$\begin{array}{l}\text { Soledad } \\
\text { School } \\
(n=49)\end{array}$} \\
\hline & $\begin{array}{l}\text { HCS } \\
(n=221)\end{array}$ & $\begin{array}{l}\text { School } \\
(n=138)\end{array}$ & $\begin{array}{l}\text { HCS } \\
(n=34)\end{array}$ & $\begin{array}{l}\text { School } \\
(n=36)\end{array}$ & $\begin{array}{l}\text { HCS } \\
(n=81)\end{array}$ & $\begin{array}{l}\text { School } \\
(n=76)\end{array}$ & $\begin{array}{l}\text { School } 1 \\
(n=226)\end{array}$ & $\begin{array}{l}\text { School } 2 \\
(n=97)\end{array}$ & $\begin{array}{l}\text { School } 3 \\
(n=28)\end{array}$ & \\
\hline Parasitism & $42.1^{\text {a) }}$ & $56.5^{\mathrm{b})}$ & $44.1^{\mathrm{a})}$ & $55.6^{a)}$ & $51.8^{\mathrm{b})}$ & $77.6^{c)}$ & $61.5^{\mathrm{b})}$ & $70.1^{c)}$ & $64.3^{\mathrm{b})}$ & $73.5^{c)}$ \\
\hline Helminths & $4.1^{\mathrm{a})}$ & $13.0^{\mathrm{b})}$ & $5.9^{\text {a) }}$ & $5.6^{\mathrm{a})}$ & $17.3^{\mathrm{b})}$ & $14.5^{\mathrm{b})}$ & $15.5^{\mathrm{b})}$ & $23.7^{c)}$ & $0^{\text {a) }}$ & $8.2^{\mathrm{b})}$ \\
\hline Protozoa & $39.4^{\mathrm{a})}$ & $52.9^{\mathrm{b})}$ & $38.2^{\mathrm{a})}$ & $55.6^{\mathrm{b})}$ & $44.4^{\mathrm{a})}$ & $77.6^{c)}$ & $54.4^{\mathrm{b})}$ & $64.9^{b)}$ & $64.3^{\mathrm{b})}$ & $73.5^{\mathrm{c})}$ \\
\hline Poly-infection & $26.9^{\mathrm{a})}$ & $43.6^{\mathrm{b})}$ & $20.0^{\mathrm{a})}$ & $55.0^{\mathrm{b})}$ & $33.3^{\text {a) }}$ & $61.0^{\mathrm{b})}$ & $38.1^{\text {a) }}$ & $52.9^{b)}$ & $27.8^{a)}$ & $50.0^{\mathrm{b})}$ \\
\hline \multicolumn{11}{|l|}{ Parasite species } \\
\hline Entamoeba hystolitica & 2.3 & 10.9 & 2.9 & 11.1 & 1.2 & 11.8 & 5.8 & 10.3 & 0 & 6.1 \\
\hline Entamoeba coli & 7.2 & 8.0 & 11.8 & 30.6 & 12.3 & 26.3 & 17.3 & 13.4 & 10.7 & 16.3 \\
\hline lodamoeba sp. & 0.5 & 0 & 2.9 & 0 & 1.2 & 0 & 0.4 & 0 & 0 & 2.0 \\
\hline Blastocystis sp. & 24.4 & 30.4 & 5.9 & 47.2 & 22.2 & 36.8 & 17.3 & 27.8 & 17.9 & 51.0 \\
\hline Giardia sp. & 11.3 & 17.4 & 11.8 & 11.1 & 8.6 & 28.9 & 10.6 & 22.7 & 32.1 & 18.4 \\
\hline Endolimax nana & 7.7 & 8.0 & 14.7 & 2.8 & 9.9 & 19.7 & 19.9 & 16.5 & 21.4 & 24.5 \\
\hline Ascaris lumbricoides & 1.4 & 4.3 & 2.9 & 0 & 4.9 & 1.3 & 7.5 & 12.4 & 0 & 0 \\
\hline Trichiuris trichiura & 1.4 & 7.2 & 0 & 2.8 & 12.3 & 11.8 & 9.7 & 16.5 & 0 & 8.2 \\
\hline Enterobius sp. & 0.9 & 0.7 & 0 & 0 & 0 & 1.3 & 0.9 & 2.1 & 0 & 0 \\
\hline Hymenolepis nana & 0.9 & 1.4 & 2.9 & 2.8 & 3.7 & 0 & 0.9 & 1.0 & 0 & 0 \\
\hline Uncinaria sp. & 0 & 0 & 0 & 0 & 0 & 0 & 0 & 1 & 0 & 0 \\
\hline Strongyloides sp. & 0 & 0.7 & 0 & 0 & 0 & 0 & 0 & 0 & 0 & 0 \\
\hline
\end{tabular}

BMA, Baranquilla metropolitan area; HCS, health centers providing services.

${ }^{\mathrm{a}-\mathrm{c})}$ Frequencies (\%) in the same row that do not share the superscript letter are statistically significantly different.

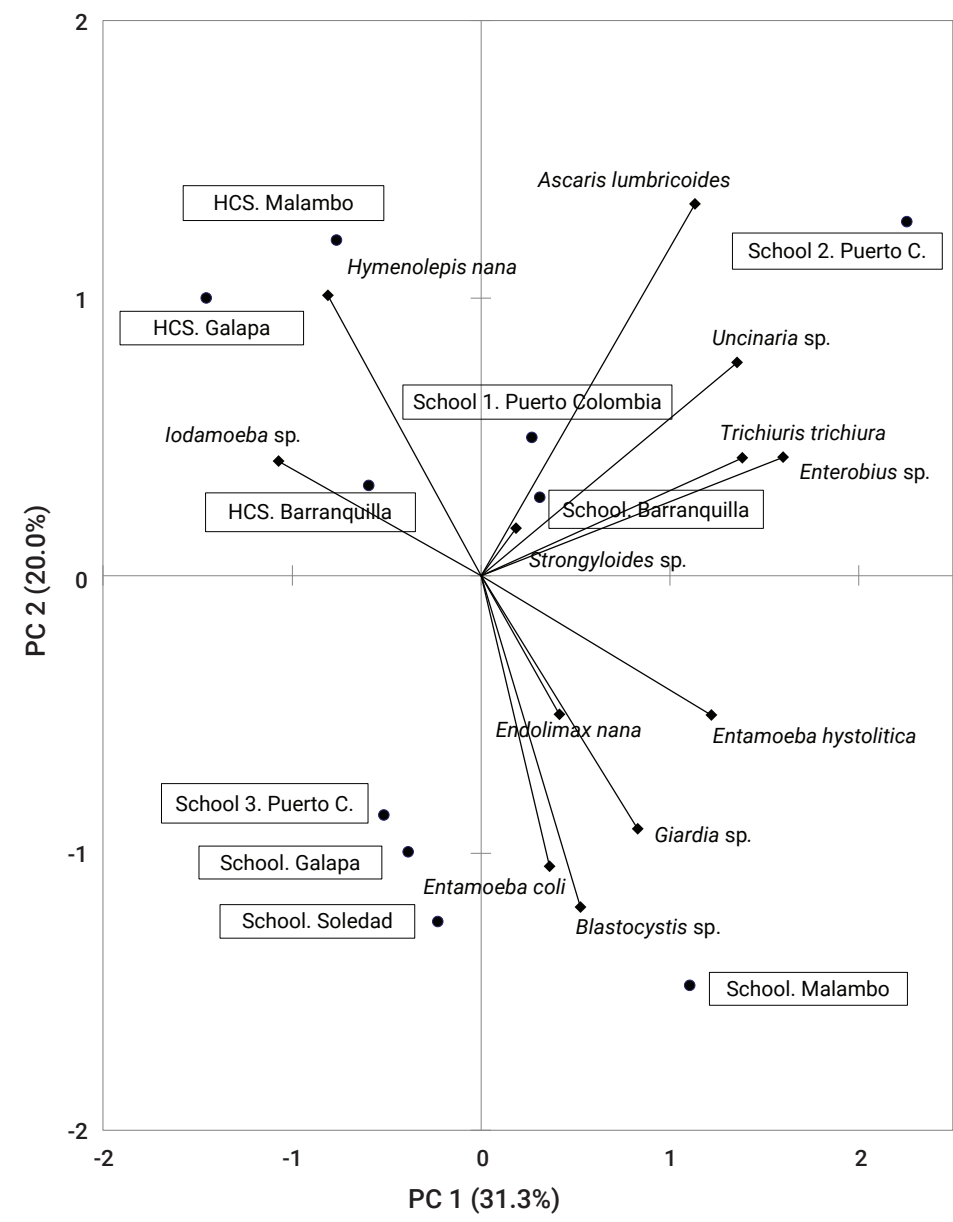

Figure 2. Principal component analysis revealing the relationships between the rates of parasites and sampling locations.

The graphic shows the cumulative variability for Principal Componet (PC) 1 and 2 (51.3\%). The parasite profiles for each sampling location shared no common characteristics that enabled them to be grouped by municipality. HCS, health centers providing services. 
the variables Endolimax nana (30.0\%), Hymenolepis nana (14.9\%), and Entamoeba hystolitica (14.7\%). PCA showed that the parasite profiles for each sampling location shared no common characteristics that enabled them to be grouped by municipality. When this analysis was conducted with intestinal protozoa parasites or helminths set as the independent variables, no relationship was observed.

The sites with the lowest rates of parasitism were located in the upper left quadrant of the chart, which corresponded to health centers providing growth and development services. In the lower left quadrant were schools, where the main type of intestinal parasitism found was intestinal parasitic protozoa. Most of the sites with high rates of helminth infection were located in the right quadrants, particularly at a school in Malambo where high frequencies of both protozoa and helminths were found.

The results of the indirect ELISA immunoassay for IgG $T$. solium antibodies detection were positive in $8(3.0 \%)$ of the 269 serum samples analyzed (90 samples from Barranquilla district, 45 from Galapa, 45 from Malambo, 44 from Puerto Colombia, and 45 from Soledad). The positive results were from 6 children from the Soledad municipality (13.3\%), 1 child from Barranquilla district (1.1\%), and 1 child from Galapa (2.2\%). The results for 5 children were in the borderline zone of the test (values between 9 and 11 standard units) according to the manufacturer's guidelines related to the technique. Two of the children were from Soledad, 1 was from the Barranquilla district, and 2 were from Galapa.

\section{Discussion}

Soil-transmitted helminth infections in general and the taeniasis/cysticercosis complex in particular are pathologies currently prioritized by the WHO, since they are considered reemerging diseases with a significant negative impact on the social and economic development of populations [15]. In this study, the prevalence of intestinal parasitism in children under 10 years of age in the BMA was $57.6 \%$, with a prevalence of helminthiasis of $12.0 \%$ and a prevalence of protozoan parasites of $53.5 \%$.

The PCA of the parasite profiles for each sampling location did not show any similarities that would have enabled the classification of parasite profiles by municipality. The individuality of the parasitic profiles of relatively proximal locations with similar climatic and cultural conditions correlates to multiple factors implicit in parasite infection. The specific conditions of small ecological niches, where genetic, physiological, nutritional, and cultural factors could have subtle variations and the complexity of the life cycle of each parasite could be favored or obstructed by specific actions, determine the status of parasitic infection at each location [16]. The variability found in this study is consistent with the findings from the most recent national survey on parasitism, which found a diversity of profiles across municipalities in the Caribbean Arid Belt region, where the BMA is located [3].

No relationship between the MPI value and parasitism was found in any of the municipalities. Lower rates of parasitism, helminthiasis, and protozoa were observed in the Barranquilla district and Galapa, which had the lowest and highest MPI values, respectively. The municipalities of Malambo and Puerto Colombia, which also had significantly different MPI values (62.5\% for Malambo and $42.3 \%$ for Puerto Colombia), showed similar rates of parasitism. In this study, the MPI value was not specified for each individual household; however, it is important to highlight that MPI values indicate the coverage of the sewage network and unsanitary environmental conditions in homes, among other factors, and that the condition of poverty is generally associated with intestinal parasitism [17-19].

Blastocystis sp., which is the most common intestinal protozoan in the world [20], was also the most common intestinal protozoan found in this study, followed by Giardia sp. These 2 parasites are primary causes of diarrhea, especially among children and immunosuppressed people. Various studies have observed zoonotic transmission of these parasite species, although the environmental conditions that favor transmission must be investigated in greater detail [21,22]. Blastocystis sp. and Giardia sp. have been found in domestic animals in different tropical regions of the world [23,24]. In 2018 a study of the Colombian Caribbean, SarmientoRubiano et al. [25] found a high rate of zoonotic transmission of intestinal parasites among dogs and cats with owners from Barranquilla city, which is an epidemiological situation that could be related to the rate of parasites found in this study. Different studies reported the presence of Blastocystis sp. in environmental water sources such as rivers and lakes, mainly in tropical areas where the water temperature favors its survival. As such, this could be a source of regular contamination with Blastocystis sp. for people who live along the river. These findings have led to the suggestion to include the detection of Blastocystis sp. in the WHO Guidelines for Drinking Water Quality [26,27]

Although few studies have sought to directly link infection with intestinal parasites and exposure to contaminated water sources, a multivariate analysis conducted in Vietnam found a statistically significant increase in the risk of helminthiasis among populations that were in direct contact with sources of contaminated water [28]. In 2018, Amoah et al. [29] found epidemiological evidence for a higher rate 
of parasitic infections associated with direct exposure to sewage or sludge and the consumption of produce grown in contaminated soil. It is possible that the Magdalena River and the swamps surrounding the BMA, which have higher rates of microbiological contamination than are permitted for agricultural and fishing use [30], can be a determining factor associated with the high frequencies of parasitism found in the municipalities of Malambo and Puerto Colombia. These municipalities are significantly affected by the Mesolandia and Mallorquín swamps, respectivelywater sources that show high levels of microbiological contamination and organic matter [31,32]. In contrast, the municipality of Galapa, which has the highest MPI value in the BMA at $79.8 \%$ and the worst indicators of excreta elimination of the evaluated municipalities [12] but is not close to any water source, had the lowest rate of helminthiasis and one of the lowest rates of parasitism.

In this study, almost 3\% of children were found to have antibodies against $T$. solium. The presence of these antibodies does not necessarily indicate active infection with the parasite; rather, it can indicate contact with the parasite at any point in an individual's life. Contact can be with the intestinal parasite form (taeniasis) or with the larval form (cysticercosis), and the presence of the antibody can be associated with noninfectious contact with the parasite [33]. The results related to the rate of IgG anti-T. solium antibodies found in this study are consistent with the $7 \%$ rate of antibodies found in a national study from 2008 of the general population of the Department of Atlántico [34]. The national rate ranges between as low as $0.5 \%$ in the Department of Caldas to as high as $40.2 \%$ in the Department of Vaupés [34]. Epidemiological studies of the rate of antibodies related to T. solium have limited diagnostic value since the presence of such antibodies only indicates contact with the parasite and not necessarily active infection. In this study, 6 of the positive cases found were children who lived in the municipality of Soledad who attended the same educational institution, which may indicate the location of an epidemic focus that should be studied further.

The results in the borderline zone of the ELISA immunoassay could be associated with cross-reactions in the test, since individuals could have been infected with $H$. nana and Echinococcus granulosus, which are also parasites that, like Taenia sp., are members of the Cestoda class [29]. In this study, the presence of $H$. nana was found in a stool sample from 1 of the children whose serological results were in the borderline zone. The difficulty of diagnosing T. solium infections reported by different authors in different contexts indicates the need to create new and more specific diagnostic tests due to the significant impact of parasites on public health.

\section{Conclusion}

The results of this study show that intestinal parasitism affects more than $50 \%$ of the population under 10 years of age in the BMA, and although the sampling locations in this analysis were both physically and culturally close and shared vastly interdependent relationships, significant differences were found in the rates of parasitism and the parasitism profiles of each location. Deficiencies in basic sanitation, poverty conditions, and the proximity to contaminated water sources were factors associated with the prevalence of intestinal parasites among children, but specific factors related to each local ecological niche also led to differences in the parasitic profiles observed, and such factors must be studied further. It is necessary to devise and implement programs for health promotion and the prevention of parasitism at a local level.

The prevalence of anti-T. solium antibodies in children was $3 \%$, which indicates early contact with the parasite and has implications related to health outcomes. New and more efficient diagnostic strategies for the detection of T. solium infections must be sought.

\section{Notes}

\section{Ethics Approval}

This study was approved by the Ethics Committee of the Metropolitan University (Reference 2014-11 of June 10, 2014) and was based on the Declaration of Helsinki and Resolution 8430 of 1993 of the Ministry of Health and Social Protection of Colombia, which establishes the scientific, technical and administrative standards for research in health. The study was classified as minimal risk.

\section{Conflicts of Interest}

The authors have no conflicts of interest to declare.

\section{Funding}

None.

\section{Availability of Data}

All data generated or analyzed in this study were included in this published article. Further data may be requested from the corresponding author.

\section{Additional Contributions}

Conceptualization: all authors; Data curation: MF, LG, MSM; Formal analysis: MCS, JEB; Investigation: all authors; Methodology: all authors; Project administration: LASR; Resources: all authors; Software: LASR; Supervision: LASR, JEB; Validation: all authors; Visualization: all author; Writing-original draft: LASR, JEB; Writing-review \& editing: all authors.

\section{References}

1. Inter-American Development Bank; Pan American Health Organization; Sabin Vaccine Institute. A call to action: addressing soil-transmitted helminths in Latin America $\&$ the Caribbean 
[Internet]. Washington, DC: Sabin Vaccine Institute; 2011 [cited 2021 Jul 9]. Available from: https://www.paho.org/hq/dmdocuments/2011/ lac-report-eng-final-3-2011.pdf.

2. Saboya MI, Catala L, Nicholls RS, et al. Update on the mapping of prevalence and intensity of infection for soil-transmitted helminth infections in Latin America and the Caribbean: a call for action. PLoS Negl Trop Dis 2013;7:e2419.

3. Ministry of Health and Social Protection of Colombia; University of Antioquia. National Survey of Intestinal Parasitism in school population 2012-2014 [Internet]. Medellin: National Faculty Public Health, University of Antioquia, Ministry of Health and the Social Protection; 2015 [cited 2021 Jul 9]. Available from: https://www. minsalud.gov.co/sites/rid/Lists/BibliotecaDigital/RIDE/VS/PP/ET/ encuesta-nacional-de-parasitismo-2012-2014.pdf. Spanish.

4. Ministry of Health and Social Protection, Subdirection of Communicable Diseases. Deworming Guideline Massive Antihelmintic, in the Framework of the Strategy "WHO Antihelminth Preventive Chemotherapy." Bogotá: Ministry of Health and Social Protection; 2013 [cited 2021 Oct 1]. Available from: https://www.minsalud.gov.co/sites/rid/Lists/BibliotecaDigital /RIDE/VS/PP/ET/lineamiento-desparasitacion-geohelmintos-2013. pdf.

5. World Health Organization (WHO). Helminth control in school-age children: a guide for managers of control programmes [Internet]. 2nd ed. Geneva: WHO; 2011 [cited 2021 Jul 9]. Available from: https:// apps.who.int/iris/bitstream/handle/10665/44671/9789241548267_ eng.pdf? sequence $=1$ sisAllowed $=\mathrm{y}$.

6. Fernandez MC, Verghese S, Bhuvaneswari R, et al. A comparative study of the intestinal parasites prevalent among children living in rural and urban settings in and around Chennai. J Commun Dis 2002; 34:35-9.

7. Rayan P, Verghese S, McDonnell PA. Geographical location and age affects the incidence of parasitic infestations in school children. Indian J Pathol Microbiol 2010;53:498-502.

8. Sinniah B, Hassan AK, Sabaridah I, et al. Prevalence of intestinal parasitic infections among communities living in different habitats and its comparison with one hundred and one studies conducted over the past 42 years (1970 to 2013) in Malaysia. Trop Biomed 2014; 31:190-206.

9. Brooker S, Clements AC, Bundy DA. Global epidemiology, ecology and control of soil-transmitted helminth infections. Adv Parasitol 2006;62:221-61.

10. World Health Organization (WHO). Guideline: preventive chemotherapy to control soil-transmitted helminth infections in at-risk population groups [Internet]. Geneva: WHO; 2017 [cited 2021 Jul 9]. Available from: https:// apps.who.int/iris/bitstream/handle/10665/258983/9789241550116eng.pdf.

11. National Administrative Department of Statistics (DANE). National and departmental population projections 2005-2020 [Internet]. Colombia: DANE; 2019 [cited 2021 Jul 9]. Available from: http://biblioteca. dane.gov.co/media/libros/estudios_postcensales_07.PDF.
12. Department of planning Governorate of the Atlantic. Plan of development 2016-2019 Atlantic leader [Internet]. Barranquilla: Governorate of the Atlantic; 2016 [cited 2021 Jul 9]. Available from: https://www.atlantico.gov.co/images/stories/plan_desarrollo/plan_ de_desarrollo_2016_2016_definitivo.pdf.

13. Faust EC, Sawitz W, Tobie J, et al. Comparative efficiency of various technics for the diagnosis of protozoa and helminths in feces. J Parasitol 1939;25:241-62.

14. Ines EJ, Pacheco FT, Pinto MC, et al. Concordance between the zinc sulphate flotation and centrifugal sedimentation methods for the diagnosis of intestinal parasites. Biomedica 2016;36:519-24.

15. World Health Organization (WHO). Working to overcome the global impact of neglected tropical diseases: first WHO report on neglected tropical diseases [Internet]. Geneva: WHO; 2010 [cited 2021 Jul 9]. Available from: https://apps.who.int/iris/handle/10665/44440.

16. Food and Agriculture Organization of the United Nations/World Health Organization (FAO/WHO). Multicriteria-based ranking for risk management of food-borne parasites [Internet]. Microbiological Risk Assessment Series No. 23. Rome: FAO/WHO; 2014 [cited 2021 Jul 9]. Available from: https://apps.who.int/iris/bitstream/handle/ 10665/112672/9789241564700_eng.pdf.

17. Thompson RC. The future impact of societal and cultural factors on parasitic disease: some emerging issues. Int J Parasitol 2001;31: 949-59.

18. Karan A, Chapman GB, Galvani A. The influence of poverty and culture on the transmission of parasitic infections in rural Nicaraguan villages. J Parasitol Res 2012;2012:478292.

19. Robertson LJ. Parasites in food: from a neglected position to an emerging issue. Adv Food Nutr Res 2018;86:71-113.

20. Clark CG, van der Giezen M, Alfellani MA, et al. Recent developments in Blastocystis research. Adv Parasitol 2013;82:1-32.

21. Thompson RC, Smith A. Zoonotic enteric protozoa. Vet Parasitol 2011; 182:70-8.

22. Robertson LJ, Clark CG, Debenham JJ, et al. Are molecular tools clarifying or confusing our understanding of the public health threat from zoonotic enteric protozoa in wildlife? Int J Parasitol Parasites Wildl 2019;9:323-41.

23. Li W, Liu X, Gu Y, et al. Prevalence of Cryptosporidium, Giardia, Blastocystis, and trichomonads in domestic cats in East China. J Vet Med Sci 2019;81:890-6.

24. Moura R, Oliveira-Silva MB, Pedrosa AL, et al. Occurrence of Blastocystis spp. in domestic animals in Triângulo Mineiro area of Brazil. Rev Soc Bras Med Trop 2018;51:240-3.

25. Sarmiento-Rubiano LA, Delgado L, Ruiz JP, et al. Intestinal parasites in dogs and cats with owners of Barranquilla, Colombia. Rev Investig Vet del Peru 2018;29:1403-10.

26. Koloren Z, Gulabi BB, Karanis P. Molecular identification of Blastocystis sp. subtypes in water samples collected from Black sea, Turkey. Acta Trop 2018;180:58-68.

27. World Health Organization (WHO). Guidelines for drinking water 
quality. 4th ed. Geneva: WHO; 2011.

28. Pham-Duc P, Nguyen-Viet H, Hattendorf J, et al. Ascaris lumbricoides and Trichuris trichiura infections associated with wastewater and human excreta use in agriculture in Vietnam. Parasitol Int 2013; 62:172-80

29. Amoah ID, Adegoke AA, Stenstrom TA. Soil-transmitted helminth infections associated with wastewater and sludge reuse: a review of current evidence. Trop Med Int Health 2018;23:692-703.

30. Garces-Ordonez O. Diagnosis and Evaluation of the quality of the marine and coastal waters of the Colombian Caribbean and Pacific [Internet]. Bogotá: Invemar Periodicals Series; 2016 [cited 2021 Jul 9]. Available from: http://www.invemar.org.co/documents/10182/14479/ Informe+REDCAM+2015_mayo2016.pdf. Spanish.

31. Garces-Ordonez O, Rios-Marmol M, Vivas-Aguas JL. Evaluation of the environmental quality of the mangroves of the Mallorquin swamp. Department of Atlántico. CRA-INVEMAR Agreement No. 027 of 2015. Final Technical Report [Internet]. Bogotá: Publications Series Periodics of Invemar; 2016 [cited 2021 Jul 9]. Available from: https:// docplayer.es/70334486-Evaluacion-de-la-calidad-ambiental-delos-manglares-de-la-cienaga-mallorquin-departamento-delatlantico.html. Spanish.
32. Atlantic Regional Autonomous Corporation (CRA). Characterization physicochemistry of waste water discharges into the water bodies of the Department of the Atlantic and monitoring of the quality and current status of the water sources of the department year 2011 [Internet]. Barranquilla: CRA; 2011 [cited 2021 Jul 9]. Available from: https://www.crautonoma.gov.co/documentos/pomcas/Recurso\%20 Hidrico/INFORME\%20FINAL.pdf. Spanish.

33. Del Brutto OH. Neurocysticercosis: up-dating in diagnosis and treatment. Neurologia 2005;20:412-8.

34. Sanchez A, Pastran SM, Vargas NS, et al. Cysticercosis in Colombia. Seroprevalence study 2008-2010. Acta Neurol Colomb 2012;29:73-86. Spanish. 